\title{
Monitoring, repair, and safety practices for electric furnace matte tapping
}

\author{
by L. Thomson*
}

\section{Synopsis}

The smelter at Sudbury Integrated Nickel Operations, located in Sudbury, Ontario, operates a single AC electric furnace. This furnace treats nickel sulphide concentrates produced by Glencore and third-party feeds, and as such its performance is critical to the company's nickel supply chain. Currently the plant has two shutdowns per year in order to carry out significant repairs on the matte tap-holes.

Improved monitoring systems that enable better prediction of tap-hole wear have been a continued focus. The electric furnace is an essential part of the smelter flow sheet, requiring planned tap-hole maintenance together with robust systems to manage to this plan.

The ability to meet our goal of zero harm depends on ensuring that safe practices are in place. Detailed procedures and cool-down practices have been implemented to ensure that the required matte chemistry and temperature criteria are met prior to a shutdown for tap-block maintenance.

A major repair of the furnace will take place in 2015. During this rebuild, the sidewalls and matte endwall will be replaced. There is work underway to improve wall and matte end performance in an attempt to extend the time between rebuilds. This paper reviews the approach taken.

Keywords

Tap-block, electric furnace, monitoring systems, safe practices, matte taphole repairs, copper coolers, lintel cooler, nickel smelter.

\section{Introduction}

The smelter at Sudbury Integrated Nickel Operations, located in Sudbury, Ontario processes approximately 550000 t of nickel-, copper-, and cobalt-bearing feeds annually. This results in an annual production of more than $70000 \mathrm{t}$ of nickel and $2300 \mathrm{t}$ of cobalt. The smelter receives concentrate from internal and custom sources. Two company-owned mines, Nickel Rim South Mine and Fraser Mine, located in Sudbury, supply the Strathcona Mill with feed for processing into nickel concentrate. The Raglan Mine in northern Quebec feeds the Raglan Mill. Raglan concentrate is shipped and railed to the smelter. Other custom feeds, comprising both concentrates and secondary materials, are also treated to maximize the smelter capacity.

A single electric furnace treats all nickel sulphide concentrates produced by Glencore as well as third-party feeds, and as such its performance is critical to the company's nickel supply chain.

Tap-hole monitoring and maintenance systems are critical for keeping high online time on this furnace. This paper will outline these systems as well as our plan for a major furnace rebuild in 2015 .

The three main topics that will be discussed in the paper are ensuring tap-hole reliability through monitoring, safety in operation and repairs, and the continued development of matte endwall performance.

\section{Smelter flow sheet description}

The flow sheet (Figure 1) consists of a feed preparation area, two slurry-fed fluid bed roasters (with acid plant), a single electric furnace, a four-vessel converter aisle, and matte granulation.

The concentrates are blended in the feed preparation area. The blended slurry at $70 \%$ solids density is fed into the two fluid bed roasters. Flux is also added to the roasters to provide a bed and to be pre-heated prior to feeding to the furnace. The roasters operate at $765^{\circ} \mathrm{C}$ and remove over $70 \%$ of the sulphur from the feed. The roaster off-gas stream is directed through the gas handling system, with the calcine dust collected and fed to the furnace and the cleaned gas sent to a single contact acid plant.

Roaster calcine from both roasters is fed into the electric furnace via drags and fettling pipes. The operating temperatures of the furnace slag range from $1350-1400^{\circ} \mathrm{C}$, while that of the furnace matte ranges from 1250 $1300^{\circ} \mathrm{C}$. The slag from the furnace is granulated and pumped to an on-site disposal area. The matte is tapped from one of three matte tap-holes into steel ladles and is transported by molten metal crane to the countercurrent converter aisle for further processing.

* Sudbury Integrated Nickel Operations, Glencore, Canada.

(C) The Southern African Institute of Mining and Metallurgy, 2016. ISSN 2225-6253. This paper was first presented at the, Furnace Tapping Conference 2014,27-28 May 2014, Misty Hills Country Hotel, Muldersdrift, South Africa. 


\section{Monitoring, repair, and safety practices for electric furnace matte tapping}

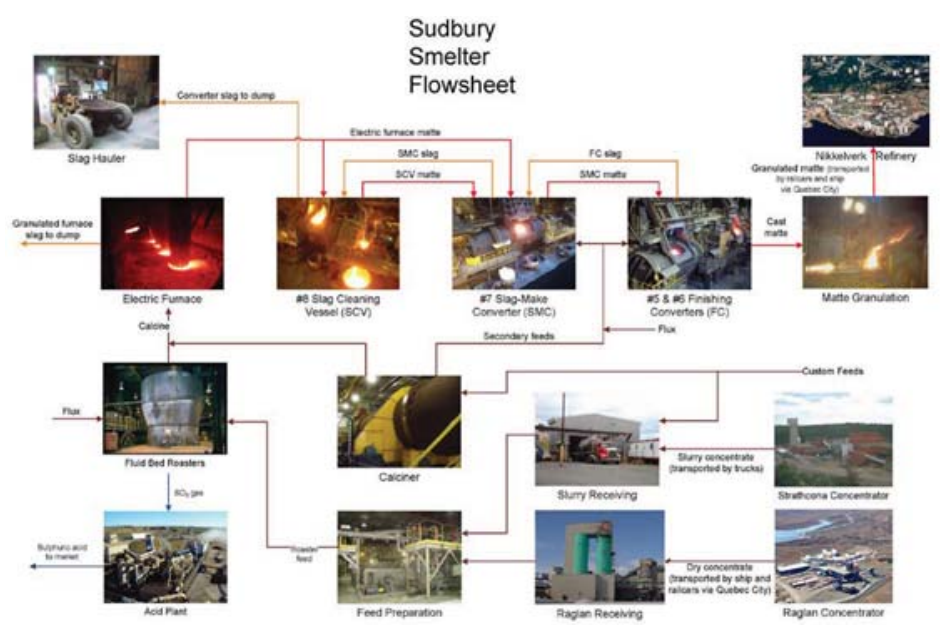

Figure 1-Smelting flow sheet at Sudbury Integrated Nickel Operations smelter

The converter aisle includes a slag cleaning vessel, slag make converter, and two identical finishing vessels.

Matte from the finishing vessels has an iron content of $2 \%$ and a pay-metal content of about $76 \%$. This finished matte is granulated, dried, and loaded into railcars for shipment to Glencore's Nikkelverk refinery in Norway.

\section{Electric furnace operation}

The furnace is a six-in-line electric furnace measuring $30 \mathrm{~m} \times$ $10 \mathrm{~m}$. The furnace operates at power levels up to $45 \mathrm{MW}$ and calcine is directed along the length of the furnace through fettling pipes toward the electrodes. A calcine layer is maintained and regular dips are taken to confirm bath levels.

As well as the calcine fed to the furnace, reverts, secondary materials, and coke are added by mixing in with the calcine in the drag conveyors. The coke is added to maintain reductive conditions and create a metallized furnace matte for improved pay-metal recoveries.

The matte fall in the furnace accounted for approximately $40 \%$ of the total calcine fed to the furnace in 2012. On average, 18 matte taps are conducted each twelve-hour shift. The nature of this process requires that furnace matte be tapped ladle by ladle, and transported via cranes to the converter aisle. Ventilation hoods over the tap-holes and launder (Figure 2) pull fume and gas to a dedicated baghouse. More information regarding the hygiene improvements in this area has been previously presented by Salt and Cerilli (2009).

The tap-hole wear at the matte end of this furnace is caused primarily by the frequent tapping and closing of the tap-holes. Water-based clay is used when plugging the holes, and boiling of this clay is a significant contributor to wear. The matte temperature is also controlled to manage tap-hole wear.

There are three matte tapping channels on the furnace, and tapping (Figure 3 ) is rotated on a shift-by-shift schedule to allow time for cooling and lengthen the time between repairs.

Regular maintenance is performed on the tap-holes, with significant repairs to the blocks in the tapping channel during shutdowns twice per year. The furnace endwalls and sidewalls are repaired only every ten years. The original furnace hearth has been in service since 1978 .

\section{Monitoring systems}

At the smelter, robust monitoring systems are used as a key means of providing information on tap-hole wear.

Multiple rows of shallow-cooled copper coolers are present on the furnace sidewalls and slag endwall. At the matte end, both shallow-cooled and deeper-cooled copper elements are used. Several thermocouples located in the copper coolers measure the cooler temperatures and this information is fed into the operating control system and data historian. Temperature and flow rate are also monitored on the cooling water streams.

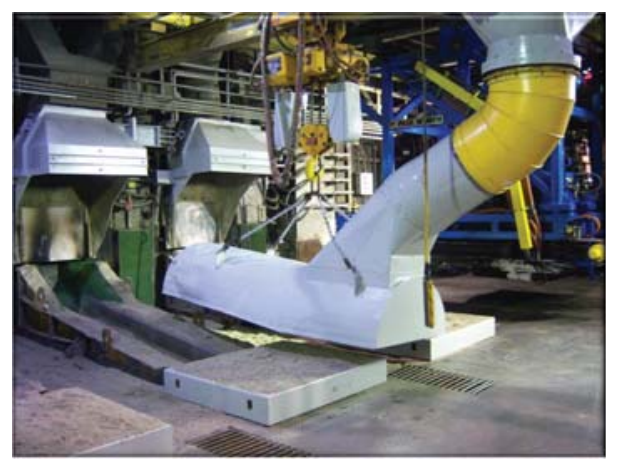

Figure 2-Matte tapping area at Sudbury Integrated Nickel Operations smelter

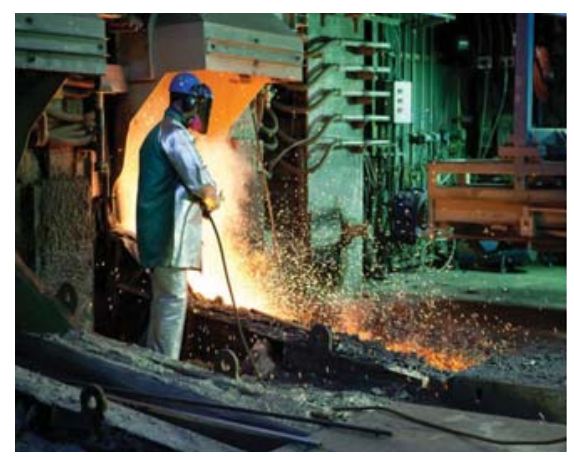

Figure 3-Matte tapping at Sudbury Integrated Nickel Operations smelter 


\section{Monitoring, repair, and safety practices for electric furnace matte tapping}

Alarms are configured into the control system to alert the control room supervisor to high temperatures and low water flow rates. Temperature alarming related to the copper blocks has been developed from heat flux modelling to ensure the protection and integrity of each copper element within its design criteria.

Specifically on the matte end tapping channel thermocouples, a predictive temperature monitoring system was installed to identify any shifts in temperature trends or unusual temperature behaviour. This system is able to identify and advise of changes even while the temperatures are still within normal values.

Fibre optic temperature measurement is also being tested on the cooling elements called 'doghouses' in two of the three matte tapping channels. The intent at this stage is to provide more resolution on the tap-hole temperatures to validate the measured trends on the existing copper cooler thermocouples. With further development, the fibre optic system may allow for better characterization of the rate of tap-hole wear.

Procedures are in place to respond to all alarms on the furnace cooling systems. Managing high temperatures on coolers at the matte end can include options such as reducing furnace power and limiting tapping from a specific tap-hole where high temperatures are detected. Tap-hole repairs may also be scheduled in response to higher temperature readings.

In general, the facility has a conservative culture when managing risk in regard to furnace integrity. Intensive reviews are completed prior to any changes to operating practices and cooler design at the matte end. The site uses a Management of Change system for tracking when changes are made to the process, practices, or equipment in the area. This system includes a formal and stepwise approval process and criteria to determine if a specific risk review assessment is required. The risk review must include representation from operators, maintenance personnel, technical resources, supervision, and joint health and safety committee members. Following the risk review, final approval is required to ensure all identified risks can be mitigated or managed prior to making the change.

For significant changes on the furnace a peer or thirdparty review may be conducted. This step is determined at the smelter management level.

There is a comprehensive risk register in place for the electric furnace integrity system to monitor key activities and track continued improvements. The key performance metrics are summarized for management on a monthly basis. All recurring activities are tracked in a risk-based document system called CURA.

The deep copper coolers at the matte end (Figure 4) have either Monel or $\mathrm{Cu} / \mathrm{Ni}$ alloy tubing and all connections for water piping are located outside the furnace wall. This set-up is the same for both the shallow- and the deep-cooled elements. Sand seals are in place above each matte end taphole covering the coolers and instrumentation cables. A moisture detection system that alarms back to the operating control system DCS is used to detect any leaks in these areas.

Several of the systems and practices in place at the Sudbury smelter have been developed through correlation of key tapping parameters with on-site monitoring of the tapblock condition during both the frequent and semi-annual block replacements, as well as during test campaigns with new deep-cooling blocks.

To date, there has been good success in managing refractory wear rates with no major events related to unexpected temperatures. The systems in place have been able to ensure appropriate response to temperature trends and for completing appropriate tap-hole repairs. During removals, the copper coolers have been found to be in good condition.

In August 2012, elevated temperatures were detected in the zone above the middle tap-hole on the deep lintel copper cooler that was being tested at that time. The monitoring systems were able to detect these temperatures and alarm appropriately. In response to these temperature trends, tapping times on this hole were reduced, allowing for time to plan for repair in this tapping channel and removal of the deep lintel for inspection. Further information on the deep lintel development is given below.

\section{Tap-hole repairs - ensuring safety}

To maintain tap-hole integrity given the high matte tapping rates on the furnace, regular first- and second-level repairs are required. To meet the goal of zero harm we want to ensure that safe practices are in place while carrying out these repairs. Prior to repair, specific criteria must be met to ensure frozen matte conditions behind the repair zone.

Over the years, detailed procedures and cool-down practices have been implemented to ensure that the required matte chemistry and temperature criteria are met prior to repair. The philosophy behind the cool-down practice is to ensure there is solid material ten inches past the working face.

Prior to a scheduled tap-block repair, the tap-hole is taken out of service to allow for cooling. An air sparge may also be used to increase the rate of cooling.

In the first two levels of repair, molten conditions still exist behind the frozen matte. In the highest level of repair, conducted during twice-annual shutdowns, the furnace level is reduced, cold charge material is added behind the tap-hole, and power is reduced to ensure frozen conditions behind all tap-holes on the matte endwall.

With the exception of the first-level repair, a stainless steel sheath is inserted in the matte tap-hole at least 24 hours ahead of the planned repair. The hollow sheath is inserted ten inches past the planned working face. The depth for sheath installation will change based on the specific number of blocks to be repaired. Two thermocouples are

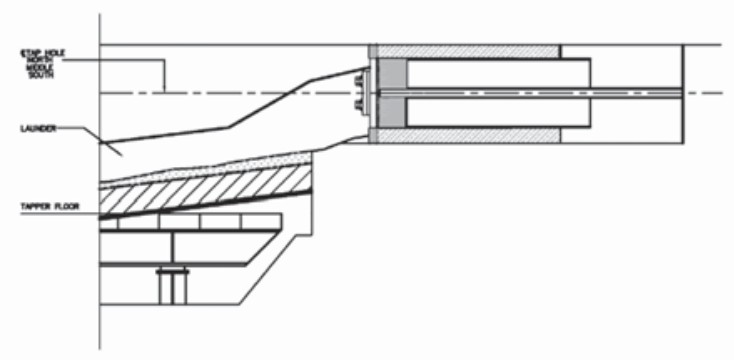

MATTE END TAP-HOLE SECTION 


\section{Monitoring, repair, and safety practices for electric furnace matte tapping}

inserted inside the sheath to measure both the working face temperature and the temperature ten inches past it. These thermocouples are connected to the operating DCS for trending the cooling rate and remain in place until the start of the repair.

Once the sheaths are in place, the roaster rate and power input are controlled to ensure that matte temperature, matte superheat, and bath level criteria are met for the start of the repair. Temperature and chemistry data is reviewed by the leader of the repair crew on the morning of the repair. If the outlined criteria are not met, further discussion must be held to assess risks and determine if the repair is to proceed.

The furnace operates with a metallized matte. This degree of metallization is controlled during the time leading into repairs. For the third-level repairs, the metallization is lowered to aid in chipping of the matte plug.

Table I summarizes the criteria for three typical levels of tap-block repairs.

\section{Development of deeper cooling on the matte endwall}

The most recent furnace wall rebuild was in 2004. For the five years following this wall rebuild, very few elevated temperatures were detected in the tapping channels. In June 2009, elevated temperatures began occurring in the tapping channels toward the end of the campaigns. In the last few years, elevated temperatures have required close management of tap-hole rotation leading up to each of the major repairs.

Since 2009, work has been underway to improve the wall and matte end performance in an attempt to extend the time between rebuilds. The goal is to improve the design such that elevated temperatures are eliminated, allowing regular tapping rotation to be maintained up to the end of the campaigns. This improvement would provide greater flexibility on the timing for the twice-annual maintenance outages.

With higher nickel production targets continuing to be achieved at similar smelter feed grades, a higher throughput is required in the two roasters and furnace. Given the single furnace operation and close tie-in to the converting aisle, the required matte tapping rates per shift have increased. To increase smelting rates, the matte temperatures and superheats have also been increased. Figure 5 summarizes the matte taps per day on an average annual basis since
2008. Average daily tapping rates for 2013 are $28 \%$ higher than in 2008.

Until three years ago, repairs were made to the matte tapping blocks twice per year, with the cooling elements, specifically called the doghouses, being pulled out only once per year to allow for bricking repair in front. Based on the increased temperatures being recorded on the cooling elements, this strategy has been changed, with the doghouse now being pulled during both of the two outages to allow for more extensive repairs.

In 2009, in response to elevated temperatures on the doghouse cooling blocks, the focus was to develop deeper cooling above the tapping channel (Figure 6). The objective is to extend the matte endwall life by extending the tapping channel away from the doghouse edge.

The initial design for the deep lintel was for a larger copper cooler with refractory lining at the hot face to be inserted past the doghouse in order to push out the isotherm. This lintel (Figure 7) was installed on the middle tap-hole in the summer of 2011 and remained in service for two sixmonth campaigns. The deeper cooling above the tapping channel was found to be successful in protecting the doghouse from elevated temperatures. However, elevated temperatures that required closer management occurred near the end of the campaigns on the deep lintel cooler itself.

The second design (Figure 8) incorporated a graphite block at the hot face that was installed on the middle tap-hole in the summer of 2012. After two months' service, elevated temperatures were measured on this block. The tapping on

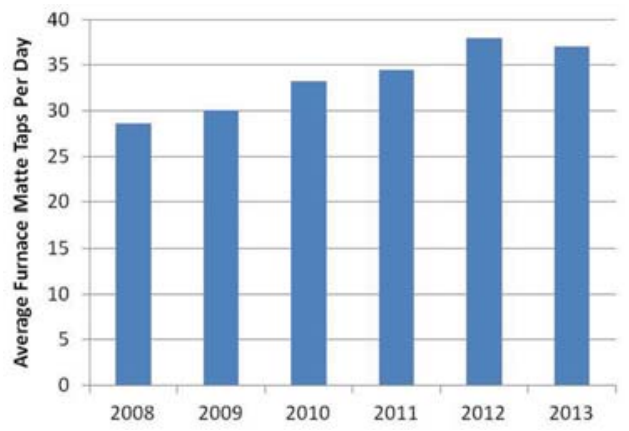

Figure 5-Furnace matte taps averaged on an annual basis for the last 5 years

Table I

Summary of criteria for matte tap-hole repairs

\begin{tabular}{|l|c|c|c|c|c|}
\hline $\begin{array}{l}\text { Level of tap- } \\
\text { block repair }\end{array}$ & $\begin{array}{c}\text { Cool down } \\
\text { time (h) }\end{array}$ & $\begin{array}{c}\text { Temperature criteria } \\
\text { (Must be met prior to repair) }\end{array}$ & Bath level criteria & $\begin{array}{c}\text { Superheat } \\
\text { criteria (deg C) }\end{array}$ & Other steps \\
\hline First Level & Min $24 \mathrm{~h}$ & $\begin{array}{c}\text { T/C inserted to working face } \\
\text { depth - ensure frozen conditions }\end{array}$ & $\begin{array}{c}\text { Total bath and matte level at } \\
\text { normal operating levels }\end{array}$ & $\begin{array}{c}\text { matte }<150 \\
\text { Temp check on each block } \\
\text { during removal }\end{array}$ \\
\hline Second Level & Min 24 $\mathrm{h}$ & $\begin{array}{c}\text { Sheath inserted 10" past working face. } \\
\text { Two T/Cs to measure temp 10" past } \\
\text { and temp at working face }\end{array}$ & $\begin{array}{c}\text { Total bath and matte level } \\
92 \% \text { of normal operating } \\
\text { levels }\end{array}$ & $\begin{array}{c}\text { matte }<100 \\
\text { Roaster rate limited once sheaths } \\
\text { in place, phase } 1 \text { (matte end) } \\
\text { power idle }\end{array}$ \\
\hline Third Level & Typical 48-72 h & $\begin{array}{c}\text { Sheath inserted 10" past working face. } \\
\text { Two T/Cs to measure temp 10" past } \\
\text { and temp at working face }\end{array}$ & $\begin{array}{c}\text { Total bath } 50 \% \text { of normal } \\
\text { operating levels, slag } \\
\text { present at matte taphole level }\end{array}$ & $\begin{array}{c}\text { matte }<100, \\
\text { slag }<100\end{array}$ & $\begin{array}{c}\text { Roasters off, phase 1 power off, } \\
\text { cold charge and roof T/Cs inserted } \\
\text { and trended }\end{array}$ \\
\hline
\end{tabular}




\section{Monitoring, repair, and safety practices for electric furnace matte tapping}

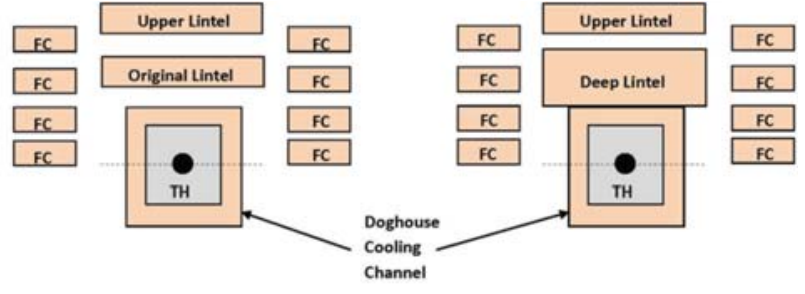

FC-Flanker Copper Coolers

TH - Tap-Hole

Figure 6-Schematic of matte end tap-hole design front view. Left: original design, right: current design

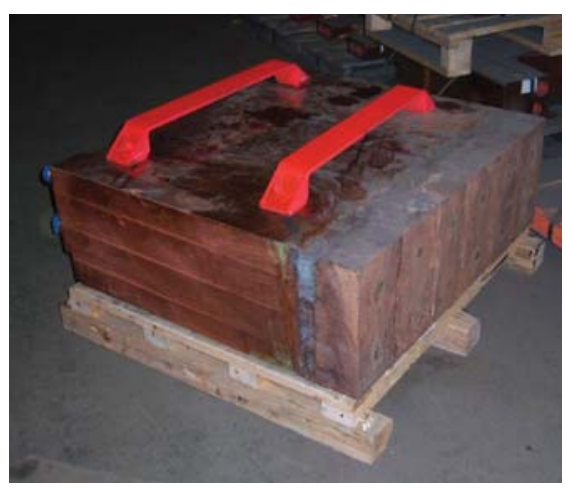

Figure 7-Refractory-lined copper deep lintel

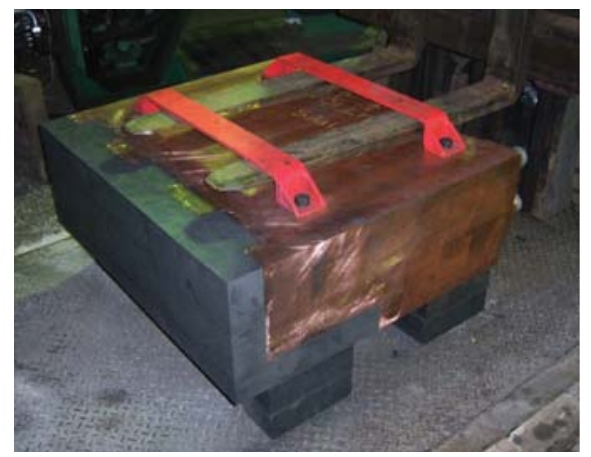

Figure 8-Graphite-lined copper deep lintel prior to installation

this tap-hole was reduced to manage the temperatures, and after one month the tap-hole was taken offline to complete a tap-hole repair and removal of the graphite-lined copper lintel. At this time, the refractory-lined copper lintel was put back in service.

Upon removal and inspection, the graphite was found to be worn back in the bottom section (Figure 9), consistent with the location of the thermocouples where the highest temperatures were recorded. Further analysis showed that, given the elevation of the lintel cooler near the slag-matte interface, maintaining an adequate build-up layer was difficult. At the furnace re-start in June 2012 with the new cooler in place, the solid slag build-up in front of the cooler was present, but with time and tapping frequency, this buildup could not be maintained to provide an adequate protective layer in front of the cooler (Cerilli, 2012).

\section{Furnace wall rebuild in $\mathbf{2 0 1 5}$}

The last major repair to the furnace was conducted in June 2004 when the sidewalls, endwalls, and arched roof were rebuilt. Copper cooling on the furnace was also improved at this time, with the previous finger cooler arrangement being replaced by a plate cooler design.

A significant repair of the furnace is planned for 2015. During this rebuild, the sidewalls and both endwalls will be repaired.

The walls have been in place for nine years and have worn back over time. Currently, the wall thickness limits the extent of repair in the tapping channel and ultimately the ability to shift the matte isotherm.

The new bricking of the matte endwall will improve the wall condition. This, together with the improved cooler design, will allow for more refractory to be installed and maintained in front of the coolers during the twice-annual shutdowns.

While the deep lintel has improved protection of the doghouse, trials have proven the need for further improvement to the upper wall zone above the deeper lintel. Thermal modelling has also been carried out to confirm the impacts on the matte tidal zone and isotherms in the area.

With the upcoming furnace wall rebuild, plans are in place to incorporate deeper cooling elements higher up the endwall. This arrangement is expected to allow for a more robust matte end design as well as enable deeper refractory repair with proper tie-in support from above to keep the refractory securely in place during operation.

The current repair procedure for removing the doghouse while supporting the upper wall relies on the installation of temporary jacks. When the jacks are in place, access to the area for repair is very tight, making the installation awkward. As a result of the new supporting system and the new bridge cooler design, these jacks will no longer be required. Improvements to the repair procedure are expected owing to better access, ultimately allowing for a deeper refractory replacement.

On the future design, while the cooling blocks will be pushed deeper, it is planned for the bridge lintel cooling coil to extend past the doghouse but still within the deep lintel and plate cooler to minimize the risk of matte attack.

Additional cooling water piping will be added to the matte end of the furnace. Currently, several coolers are tied into each cooling water line. Inlet and outlet temperatures and water flow rates are monitored on each line and no major

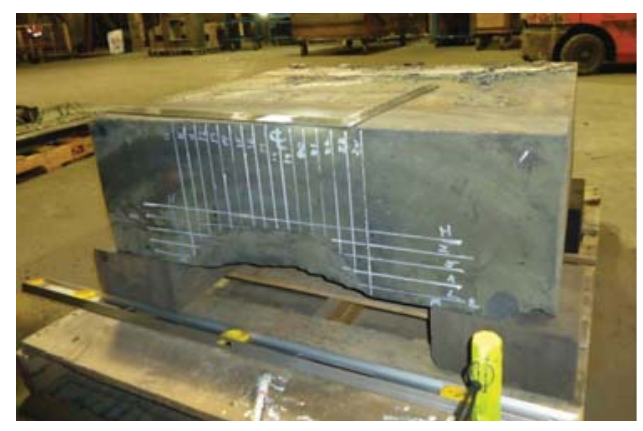

Figure 9-Graphite-lined copper deep lintel removed in September 2012 


\section{Monitoring, repair, and safety practices for electric furnace matte tapping}

deficiencies have been seen. However, having many coolers on one line complicates the ability to detect a rise in temperature on an individual cooler. With the new piping, key coolers will be placed on dedicated cooling lines to improve resolution on this aspect.

\section{Summary}

The single electric furnace at the smelter at Sudbury Integrated Nickel Operations is a key element in the company's nickel supply chain, requiring robust systems to ensure optimal furnace integrity and long campaign life.

Development work continues on improving the monitoring systems to provide a better prediction of tap-hole refractory wear.

With the high matte tapping rates due to the nature of the process, frequent tap-hole repairs are required on the tapping blocks. Repair procedures and cooldown practices have been implemented and are followed closely to ensure that required matte chemistry and temperature criteria can be met during the period leading into a shutdown for tap-block maintenance.

Development work to improve matte end performance has been underway since 2009, and has focused on deeper cooling elements above the tapping channel and deeper installation of refractory to extend the tapping channel away from the doghouse edge.

A significant repair of the electric furnace will take place in 2015 and will incorporate improvements to the matte endwall.

\section{References}

CerILLI, E. 2012. Findings on removal of graphite deep lintel. Internal Communication, Sudbury Integrated Nickel Operations, Sep. 29, 2012

SALT, B and CERILLI, E. 2009. Evolution of the converter aisle at Xstrata Nickel's Sudbury Smelter. The Minerals, Metals \& Materials Society Conference, San Francisco, CA. 